\title{
Pulmonary Arteriovenous Malformation as a Cause of Embolic Stroke: Case Report and Review of the Literature
}

\author{
Sabrina Anticoli ${ }^{a} \quad$ Francesca Romana Pezzella $^{a}$ Antonio Siniscalchic \\ Luca Gallellid, e Maria Cristina Bravi $^{b}$ \\ ${ }^{a}$ Stroke Unit Emergency Department and ${ }^{b}$ Internal Medicine Department, \\ S. Camillo-Forlanini Hospital, Rome, ' Department of Neurology, Annunziata Hospital, \\ Cosenza, ${ }^{d}$ Department of Health Science, School of Medicine, University of Catanzaro,

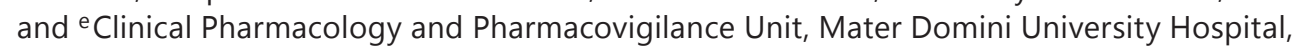 \\ Catanzaro, Italy
}

\section{Key Words}

Acute cerebral ischemia - Pulmonary arteriovenous malformation · Warfarin

\begin{abstract}
Background: Pulmonary arteriovenous malformation (PAVM) is an abnormal communication between pulmonary arteries and veins responsible for right-to-left shunting that could induce the development of embolic stroke. Summary: We describe an 82-year-old woman without history of respiratory or neurological diseases, who presented at our observation unit with acute onset of cerebral ischemia. Clinical, laboratory and radiological findings diagnosed a PAVM. Key Messages: Usually, endovascular procedures based on embolization or, alternatively, surgery represent the recommended treatment. However, both hormonal therapy and thrombolytic therapy can be used. In our patient, treatment with warfarin induced a remission of symptoms. This strategy should be tested in larger studies.

(C) 2014 S. Karger AG, Basel
\end{abstract}

\section{Introduction}

Pulmonary arteriovenous malformation (PAVM) causing stroke due to paradoxical brain embolism is rare [1,2]. Usually, PAVMs can be treated with endovascular procedures [3, 4] or, alternatively, surgery $[4,5]$; however, hormonal therapy may be indicated in order to protect the vessel wall [6]. We present a first report on the use of oral anticoagulant in an 82-year-old woman with ischemic stroke due to embolism from PAVM. 
Anticoli et al.: Pulmonary Arteriovenous Malformation as a Cause of Embolic Stroke: Case Report and Review of the Literature
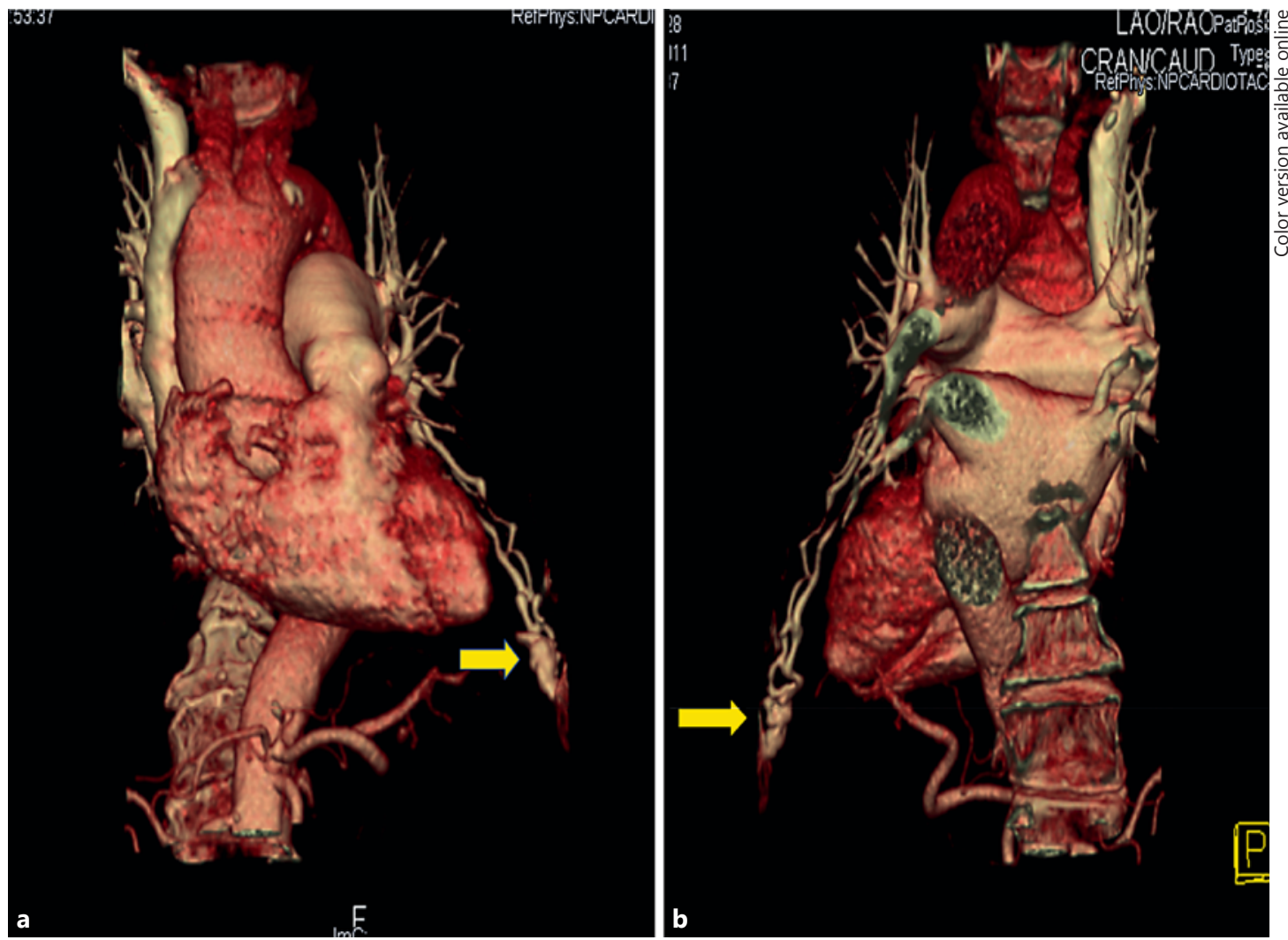

Fig. 1. Three-dimensional reconstructions using a volume-rendering technique demonstrate PAVM in the lower zone of the lingula (arrows in $\mathbf{a}$ and $\mathbf{b}$ ).

\section{Case Report}

An 82-year-old woman presented at our Emergency Department with dizziness and left-side motor weakness. Her medical history was unremarkable, and electrocardiography (ECG) was unremarkable for arrhythmias. Computed tomography (CT) did not show acute lesions, although previously, it showed left cerebellar and mesial right temporo-occipital ischemic lesions, without clinical features of Rendu-OslerWeber disease. The patient was not suitable for thrombolysis due to uncertain onset time; therefore, she was admitted to the Stroke Unit. Her National Institutes of Health Stroke Scale (NIHSS) score was 3, significant for mild left-side motor weakness and left dysmetria. During the hospital stay, she was monitored by continuous ECG and for vital parameters without any abnormalities. A brain magnetic resonance imaging (MRI) done within $24 \mathrm{~h}$ after hospital admission showed, on DWI sequences, multiple areas of abnormal signal in the mesial right temporoparietal region, left cerebellar vermis, left cerebellar hemisphere, thalamic-capsular region and right frontal cortex-opercular region, all suggestive of acute ischemic stroke. A duplex ultrasound of the carotid vessels showed bilateral common carotid artery wall thickening without significant stenosis. Atrial fibrillation was ruled out at the 24-hour Holter ECG. In order to complete the diagnostic workup, a contrast echocardiography with shaken saline i.v. injection was done, which showed a delay of 10 cardiac cycles before the injected contrast appeared in the left atrium. Therefore, a PAVM was suspected and then confirmed through lung computed tomography angiography (CTA). The 3-dimensional reconstruction showed a lesion of $2.5 \times 1.3 \mathrm{~cm}$ in the lower portion of the lingula with marked enhancement of the arterial phase and rapid washout throughout the further scans.

The lesion showed arterial afferents from the descending branch of the left pulmonary artery and efferent veins going to the left superior pulmonary vein (fig. 1). No abnormalities were shown on the lung parenchyma. 
Anticoli et al.: Pulmonary Arteriovenous Malformation as a Cause of Embolic Stroke: Case Report and Review of the Literature

The patient refused consent for a selective pulmonary arteriography, and 10 days later, she was discharged on warfarin treatment, with a recommended international normalized ratio range between 2 and 3. Follow-up was performed every 6 months, and 2 years after the first admission, we documented a persistent mild left hemiparesis without development of stroke or bleeding events.

\section{Discussion}

PAVM is an abnormal communication between pulmonary arteries and veins responsible for right-to-left shunting [7]. It is a rare condition generally detected on autopsy. About $53-70 \%$ of PAVMs are found in the lower pulmonary lobes and may be involved in $30 \%$ of right-to-left shunting [8], leading to acute cerebrovascular events. PAVMs are congenital or acquired, occurring at a frequency of $0.02 \%$ [7]. More than $50 \%$ of patients with PAVM are associated with hereditary hemorrhagic telangiectasia or Rendu-Osler-Weber syndrome [1, 8], while isolated PAVMs are uncommon. To date, only few case reports of cryptogenic stroke from isolated PAVM have been described $[1,2,9]$.

Many other conditions such as hepatic cirrhosis, mitral stenosis, Fanconi syndrome, schistosomiasis, metastatic thyroid carcinoma, bronchiectasis and overall hereditary hemorrhagic telangiectasia could be characterized by a hemodynamic dysfunction [7].

In this study, we report on an elderly woman without history of respiratory or neurological diseases, who presented at our unit with acute onset of cerebral ischemia. Neuroimaging showed multiple acute brain lesions suggestive of embolic ischemic stroke. The exclusion of common causes of thromboembolism and the evidence of right-to-left shunting on contrast echocardiography raised the suspicion of PAVM, which was confirmed by angiopulmonary CT scan. Surgery- and catheter-based approaches have been used in the management of PAVM, and patients with progressive PAVM enlargement, symptomatic hypoxemia, brain abscess or stroke are candidates for local excision, lobectomy or pneumonectomy $[4,5,10]$. However, Cartin-Ceba et al. [11], reviewing literature data, report that surgery is reserved for patients who are not candidates for embolization. In effect, most isolated PAVM closures can be accomplished by interventional catheterization using various coils for small-to-moderate sized fistulae [2] and devices such as Amplatzer vascular plugs for larger fistulae [12]. The potential complications of this antegrade approach include air embolism, paradoxical embolization of the device, spontaneous balloon deflation, pleurisy, recanalization and coil migration $[13,14]$. A transcatheter closure of a large PAVM by antegrade device closure of feeders as well as transseptal retrograde closure of the exiting channel may represent a successful endovascular procedure for the treatment of PAVM [14]. Percutaneous rerouting of the hepatic venous flow may represent a viable alternative for the treatment of PAVM [15]. In asymptomatic patients with PAVM, treatment with estrogens can preserve the vessel wall integrity while reducing the risk of bleeding [6]. In contrast, in a patient with embolic ischemic stroke in the presence of PAVM, thrombolytic therapy may be used [16].

Our patient, properly informed on the risks and benefits of each indicated treatment, refused any invasive or surgical procedure. Estrogen treatment was excluded for the probable cardiovascular and thromboembolic risk. Therefore, a long-term treatment with oral anticoagulant therapy for secondary stroke prevention was prescribed. This therapeutic decision was taken considering the risk of bleeding of the arteriovenous malformation, the stroke recurrence risk and her past medical history, which was unremarkable for any bleeding episode. 


\section{Conclusion}

About $15 \%$ of strokes are of unknown origin, while an uncertain or unclear cause is sometimes defined as 'unknown', and rare causes for stroke are overlooked. Our case history could be paradigmatic of a rare cause of stroke, eventually raising physicians' attention when looking for rare causes of very common diseases. In our patient with ischemic stroke due to embolism from the PAVM, a long-term treatment with warfarin represented a good therapeutic option for secondary stroke prevention. This strategy should be tested and validated in larger clinical trials.

\section{Disclosure Statement}

We have not received funding for our research. No conflicts of interest exist.

\section{References}

1 Husain Z, Vuppali M, Hussain K, Khan MN, Patel K, Forbes T, Bander JJ, Gowda ST: An isolated fistula between the right pulmonary artery and the right pulmonary vein: an unusual cause of stroke in a young female. Cardiol J 2011;18:73-76.

-2 Kimura K, Minematsu K, Nakajima M: Isolated pulmonary arteriovenous fistula without Rendu-Osler-Weber disease as a cause of cryptogenic stroke. J Neurol Neurosurg Psychiatry 2004;75:311-313.

-3 Oh PC, Kang WC, Choi DY, Choi IS, Lee SM, Byun SS: Successful percutaneous endovascular retrieval of a coil in the left ventricle which migrated during embolization for pulmonary arteriovenous malformation. Int J Cardiol 2013;163:e33-e35.

-4 Parshin VD, Biriukov IuV, Puretskiŭ MV, Parshin VV, Ippolitov LI, Khuan Iu: Surgical and endovascular treatment of lung arteriovenous malformations (in Russian). Khirurgiia (Mosk) 2013;10:4-11.

5 Pejhan S, Rahmanijoo N, Farzanegan R, Rahimi M: Surgically treatable pulmonary arteriovenous fistula. Ann Thorac Cardiovasc Surg 2012;18:36-38.

6 Noll G, Lüscher TF: The endothelium in acute coronary syndromes. Eur Heart J. 1998;19(suppl C):C30-C38.

7 Gossage J, Kanj G: Pulmonary arteriovenous malformations. Am Respir Crit Care Med 1998;158:643-661.

-8 R Cohen, L Cabanes, C Burkel, Duboc D, Tou E: Pulmonary arteriovenous fistulae thrombosis responsible for recurrent stroke. J Neurol Neurosurg Psychiatry 2006;77:707-708.

-9 Veeram Reddy SR, Patel VG, Gualano SK: Amplatzer vascular plug IV for occlusion of pulmonary arteriovenous malformations in a patient with cryptogenic stroke. Ann Pediatr Cardiol 2014;7:145-147.

10 Parker C, Rousan TA, Abu-Fadel M: Transcatheter closure of a pulmonary arteriovenous malformation in a patient with hereditary hemorrhagic telangiectasia. Cardiovasc Interv Ther 2014, Epub ahead of print.

11 Cartin-Ceba R, Swanson KL, Krowka MJ: Pulmonary arteriovenous malformations. Chest 2013;144:10331044.

12 Kucukay F, Ozdemir M, Senol E, Okten S, Ereren M, Karan A: Large pulmonary arteriovenous malformations: long-term results of embolization with AMPLATZER vascular plugs. J Vasc Interv Radiol 2014;25:1327-1332.

13 Lee DW, White RI Jr, Egglin TK, Pollak JS, Fayad PB, Wirth JA, Rosenblatt MM, Dickey KW, Burdge CM: Embolotherapy of large pulmonary arteriovenous malformations: long-term results. Ann Thorac Surg 1997;64: 930-940.

14 Thakkar BM, Shah J, Shukla A: Transcatheter device occlusion of a large pulmonary arteriovenous fistula by exit closure: the road less travelled. J Invasive Cardiol 2014;26:E1-E4.

-15 Dori Y, Sathanandam S, Glatz AC, Gillespie MJ, Rome JJ: Catheter approach to redirect hepatic venous return for treatment of unilateral pulmonary arteriovenous malformations after fontan. Catheter Cardiovasc Interv 2014;84:86-93.

16 Li Y, Margraf J, Kluck B, Jenny D, Castaldo J: Thrombolytic therapy for ischemic stroke secondary to paradoxical embolism in pregnancy: a case report and literature review. Neurologist 2012;18:44-48. 